\title{
Differentiated Instruction in Practice: Curriculum Adjustments in Kindergarten
}

\author{
Anastasia Mavidou, Domna Kakana \\ School of Early Childhood Education, Aristotle University of Thessaloniki, Thessaloniki, Greece \\ Email: anmavido@gmail.com,dkakana@gmail.com
}

How to cite this paper: Mavidou, A., \& Kakana, D. (2019). Differentiated Instruction in Practice: Curriculum Adjustments in Kindergarten. Creative Education, 10, 535-554.

https://doi.org/10.4236/ce.2019.103039

Received: February 12, 2019

Accepted: March 4, 2019

Published: March 7, 2019

Copyright $\odot 2019$ by author(s) and Scientific Research Publishing Inc. This work is licensed under the Creative Commons Attribution International License (CC BY 4.0).

http://creativecommons.org/licenses/by/4.0/

(c) (i) Open Access

\begin{abstract}
The present study aims to investigate the effectiveness of Differentiated Instruction (DI) on kindergarten children's achievement. More specifically, the paper discusses the effect of different types of adjustments on an Integrated Curriculum following the DI approach. DI is a teaching and learning approach that provides a context to adjust sufficiently several aspects of the curriculum in order to address effectively the needs of all learners. However, the impact of DI is often related to several learning subjects, e.g. reading, mathematics etc., while scarce empirical evidence exists regarding its effectiveness in the context of an Integrated Curriculum. The majority of related research excludes the preschool education; hence, more research about the appropriate implementation of DI in kindergarten settings is needed. The study was quasi-experimental, including pre- and post-tests to examine the effectiveness of DI in reaching the learning goals of three interventions. The participants were 80 kindergarteners for the experimental group and 74 children comprised the control group. The statistical analysis highlighted the positive impact of DI on their achievement. In addition, a tendency was found implying that differentiation by interests was the most effective type of adjustment. The results proved the applicability and positive impacts of DI in kindergarten classrooms, while further research is needed to define and optimize the differentiation strategies and techniques.
\end{abstract}

\section{Keywords}

Differentiated Instruction, Integrated Curriculum, Kindergarten, Achievement, Children's Characteristics

\section{Introduction}

Brain research has brought in the limelight three basic principles that underline the need to change the traditional methods of teaching (Tomlinson \& Kalbfleisch, 
1998). The first principle is that learning occurs when the child feels safe, because otherwise intense pressure and rejection set all the neurophysiological functions towards self-protection, and hence constrain the learning process (Dimitropoulou, 2013). Secondly, a learning environment that welcomes every difference and provides appropriate challenge to everyone enhances the self-efficacy and facilitates learning (Subban, 2006; Tomlinson \& Kalbfeisch, 1998). Finally, learners need to construct the new ideas upon their existing ideas and skills, so as the learning is meaningful for them (Tomlinson, 1999). Therefore, any teaching approach that sidelines children's characteristics is determined to be ineffective and prejudicial for some learners (Levine, 2003). Apparently, teachers have to deal with the challenge of supporting concurrently those who are in an advanced level and those who have difficulties in achieving educational goals (Heacox, 2002). The concern that emerges is which modifications can provide an effective context to address sufficiently and successfully the needs of all the children, thus limiting the school failure phenomenon.

The Differentiated Instruction (DI) is suggested as the teaching and learning approach that focuses on children's needs and is designed according to each student's characteristics. DI is applied through various curriculum adjustments that are expected to increase the effectiveness of the instruction. The present study focuses on the specific curriculum adjustments, according to DI, and their impacts on the Greek kindergarteners.

\section{Differentiated Instruction}

Differentiated Instruction (DI) is an innovative teaching approach which accepts the basic principle that children differ one from another in a variety of ways. Consequently, the instruction that is designed to be the same for all the students in a classroom is destined to fail, at least for many of them. The DI approach respects the different learning styles, the personal learning pace, and the various interests and provides a teaching and learning context that responds to such differences (Tomlinson, 1999; Tomlinson \& Kalbfeisch, 1998). Indeed, it proposes that every child deserves to engage in meaningful and worthwhile learning activities that are challenging, interesting, important and enjoyable (George, 2005; Subban, 2006).

According to Tomlinson (2001), DI is clearly a child-centered teaching approach, while the teacher organizes the appropriate learning opportunities, as s/he knows deeply the children of the classroom. Nonetheless, the teacher does not have to address every possible difference or design individualized instruction, but respond to emerged tendencies and levels that occur inside any classroom, after constant formative assessment of children (George, 2005; Heacox, 2002; Morgan, 2014; Tomlinson, 1999).

Apparently, the main aim of DI is to increase the development of each child and lead them to academic success, since it addresses their needs and supports them through the learning procedure (Tobin \& Tippett, 2014). Although DI aims 
for all the children to achieve the same basic concepts, multiple routes are provided to assist them (Tobin \& McInnes, 2008). To that end, DI incorporates the best teaching strategies that have already been applied and proved their effectiveness (Hall, 2002; Koeze, 2007; Middendorf, 2008; Tomlinson et al., 2003).

\subsection{Curriculum Adjustments}

Tomlinson (1999) argues that differentiation is based on two pillars: the children's characteristics and the curriculum. Regarding the first pillar, the instruction can be differentiated to respond to children's readiness levels, interests or learning styles. More specifically, the learning readiness is aligned to the zone of proximal development (Vygotsky 1978), since instructional planning involves skills and concepts that are slightly more advanced than the child's level, in order to achieve learning (DeBaryshe, Gorecki, \& Mishima-Young, 2009; Tomlinson et al., 2003). The readiness level refers to the specific skills, knowledge and comprehension that the child has for the specific learning goals (Tobin \& Tippett, 2014). Consequently, to address the various readiness levels, teachers need to design tiered activities integrating a variety of sources, materials and assignments in multiple difficulty levels and provide different levels of support (Scott, Vitale, \& Mastern, 1998; Tomlinson, 2001).

The interests refer to positive feelings about something that the child considers important (Tobin \& Tippett, 2014). Therefore, differentiation by interests is possible to foster and facilitate the learning process (Heacox, 2002), and simultaneously, increase the motivation and the active engagement of learners (Elliott, Kratochwill, Cook, \& Travers, 2008). Teachers can respond to different interests by providing choices from a bouquet of activities or by encouraging an independent study on an aspect they are intensely interested in (Tomlinson et al., 2003).

The learning styles concern the preferred way of receiving and processing the information (Middendorf, 2008). As a result, teachers intentionally vary the materials they use to provide multiple ways of presenting the information, adjust the classroom environment, provide choices of processing and presenting the product of learning, in order to match their instruction to the preferred learning styles of the children (Ford \& Chen, 2001; Gregory \& Chapman, 2007; Heacox, 2002; Koeze, 2007).

The second pillar of DI is the curriculum adjustments (Scott, Vitale, \& Mastern, 1998) in content, process and product (Tomlinson, 1999). The content refers to the "what" of instruction (Gregory \& Chapman, 2007), i.e. the learning goals that children are supposed to achieve, as well as the materials and sources employed to access the content. Tiered activities or materials and provision of multiple choices aligned to learners' needs are some of the basic strategies to differentiate the content (Tomlinson, 1999).

The process concerns the "how" of the learning procedure (Ernest, Heckaman, Thompson, Hull, \& Carter, 2011), as it is related to the specific activities that teachers design to assist children in achieving the learning goals (Coubergs, 
Struyven, Vanthournout, \& Engels, 2017). Lastly, the product is the result of learning that indicates the level that the goals were achieved (Tomlinson \& Imbeau, 2010). The product depends on what children are able to create to present their new knowledge, comprehension and/or skills (Santamaria, 2009). To differentiate the product, teachers offer a range of activities according to readiness, interests and learning styles of their children (Ernest et al., 2011; Tomlinson, 1999).

\subsection{Effectiveness of DI}

Recent studies suggest that DI affects positively student performance and enhances the motivation for learning (e.g. Lewis \& Batts 2005; Reis, McCoach, Little, Muller, \& Kaniskan, 2011; Tomlinson \& McTighe, 2004). Bantis (2008) studied the effect of DI on the writing achievement of elementary children and found positive impacts. In addition, other researchers indicated the increased motivation and engagement of students from elementary (Martin \& Pickett, 2013; Tobin \& Tippett, 2014) to bachelor level of education (Konstantinou-Kantzi, Tsolaki, Meletiou-Mavrotheris, \& Koutselini, 2013; Taylor, 2015).

Another group of researchers focused on the impact of matching the instruction to the learning styles, proving the effectiveness in children's performance (Cassidy, 2004; Ford \& Chen, 2001; Ford, 1995; Landrum \& McDuffie, 2010; Pask, 1976).

Nevertheless, there are also empirical data that do not always advocate the positive impact of DI, at least not for all the children. For instance, Scott (2012) in a quasi-experimental study with $2^{\text {nd }}$ graders revealed that DI did not facilitate the mathematical performance of average level of children, but it was effective for the high achievers. Similarly, Tieso (2005) found that advanced learners are positively affected from DI than other groups of learners. Faber, Glas, \& Visscher (2018) also showed that medium and high achievers from $2^{\text {nd }}$ and $5^{\text {th }}$ grades were greatly impacted in mathematics rather than low achievers. Meanwhile, Koeze (2007) showed that DI facilitated the achievement of children from low socio-economic status, but DI's effectiveness was not repeated in the sum of students. Moreover, Little, McCoach, \& Reis (2014) studied the reading performance of middle school students and found that DI was effective in reading fluency, but not in comprehension. Such conflicting findings imply that DI might be effective for specific groups of children and under certain circumstances. However, the quality of each DI application should be taken into careful consideration, before coming to any conclusion.

On the other hand, DI is a complicated teaching approach that involves many strategies and techniques and it is not clear which of them were active during each application in the referred empirical studies (Smit \& Humpert, 2012), highlighting the necessity to study the effect of the different aspects of DI (Coubergs et al., 2017). However, the related literature indicates that the strategy of choices, differentiation by interests and flexible grouping are effective strategies on students' performance (Baumgartner, Lipowski, \& Rush, 2003; Koeze, 2007; Tieso, 
2005) and motivation (Danzi, Reul, \& Smith, 2008).

The literature review reveals that: 1) there is a considerable gap in empirical studies that applied and investigated the impact of DI (Hall, 2002; Rock, Gregg, Ellis, \& Gable, 2008; Roy, Guay, \& Valois, 2013; Scott, 2012; Tieso, 2005), and 2) the majority of the studies applied and examined the DI's effectiveness in elementary, middle and college classrooms, whilst corresponding studies in kindergarten were rarely reported. Wu \& Chang (2015) investigated the teachers' DI practices in kindergarten, but not their impact on children. Nonetheless, early childhood education philosophy is converging with differentiation (Brennan, 2008; DeBaryshe, Gorecki, \& Mishima-Young, 2009; Middendorf, 2008).

Furthermore, most empirical studies focus on the effectiveness in specific subject areas and skills, namely literacy and mathematics, that are not apparent in an Integrated Curriculum, like the existing curriculum in Greece for Kindergarten "New Curriculum for Kindergarten" (Institute of Educational Policy, 2014) that is currently on pilot phase. The Integrated Curriculum considers knowledge as a whole and not fragmented in different artificial subjects (Beane, 1991). Since the Integrated Curriculum is organized around "rich and provocative themes" (Beane, 1991: p. 11), the effectiveness of any teaching approach, in our case DI, needs to be aligned with the specific learning goals of the theme. Therefore, students' achievement cannot merely be measured by their progress in literacy and/or mathematical skills, but also to the change of their existing ideas.

According to the Institute of Educational Policy (2014) of Greece "one priority of the New Curriculum for Kindergarten is to promote the awareness and respect of differentiation among children" (p. 23). The curriculum encourages the teachers to differentiate the content, the process, the learning environment and/or the product of their teaching. Regardless of the policy guidelines, teachers in Greek kindergartens tend to employ traditional teaching methods and specifically follow a pattern of teaching that includes whole group instruction and individual assignments which are the same for every learner (Kakana \& Mavidou, 2015). As already mentioned, the traditional teaching that corresponds to an abstract medium level of the class in an ineffective approach for most of the students (Levine, 2003; Tomlinson \& Kalbfleisch, 1998; Tomlinson et al., 2003). However, considering the limited empirical data regarding the effectiveness of DI in kindergarten and the impact of different aspects of DI, it is crucial to investigate how DI could be modified for early childhood education, what specific adjustments for the curriculum could be applied and what impact they may have on kindergarteners.

In the present study we discuss the specific adjustments in an Integrated Curriculum for kindergarten according to the approach of DI, and examine whether such adjustments are effective in kindergarteners' achievement regarding the learning goals of the interventions. To this aim, three integrated themes were developed and differentiated to respond to children's readiness levels, interests and learning styles. Considering the related literature (e.g. Lewis \& Batts 2005; Reis, McCoach, Little, Muller, \& Kaniskan, 2011; Tomlinson \& McTighe, 2004), 
we hypothesized that DI adjustments would foster kindergartener's performance.

\section{Method}

The research plan was quasi-experimental, as it was impossible to assign randomly the children in the experimental and control group (Christensen, 2004). The quasi-experimental designs are usually applied when research is conducted in the real world, and random assignment of the participants in two groups is not possible. Moreover, they include comparisons between the scores of pre- and post-tests of the experimental and control group to test the hypothesis of the study.

In this paper, the two groups participated in different types of instructional approach: DI for the experimental group and instruction to the average level of the class, as teachers usually plan and apply their teaching, for the control group. The independent variable was the type of instruction and the dependent variable was the children's achievement.

\subsection{Participants}

A total of 154 kindergarten children participated in the study, allocated in 13 classrooms from 11 kindergarten schools from urban and sub-urban regions of Magnesia, Central Greece. The average age was 5 years and 2 months $(S D=$ 0.52) $(\min =4, \max =6.08$ ). Although the two groups were formed according to each teacher's willingness to apply DI, similar characteristics occurred in both groups regarding the sex and the age quota.

More specifically, the experimental group was composed of 6 classrooms from 6 different kindergarten schools, corresponding to 80 children (36 girls and 44 boys) and 6 kindergarten teachers. The average age of children was 5 years and 2 months $(S D=0.46)(\min =4.08, \max =6.08)$, while the teachers had an average of 15.3 years of experience ( $\min =11, \max =17$ ) with 3 of them holding a master's degree and the remaining 3 had a bachelor's degree.

Accordingly, the control group was composed of 7 classrooms from 5 different kindergarten schools, corresponding to 74 children ( 36 girls and 38 boys) and 7 teachers. The average age of children was 5 years and 1 month $(S D=0.58)$ $(\min =4, \max =5.9)$, while the teachers had an average of 16 years of teaching experience $(\min =12, \max =19)$. Regarding teachers' level of education, 3 of them had a master's degree, 3 graduated from a university department of education and 1 teacher graduated from the pedagogical academy and then completed the equalization program in a department of education.

Both groups did not participate in any kind of systematic instruction regarding the themes that were developed in this study (i.e. "Protection of wild animals", "Healthy lifestyle", and "Books"). Therefore, their initial ideas were formed by their previous experiences in informal contexts.

The consent of children's participation was given by the parents with their signed statement, before the study began (November 2016). Specifically, from 
190 parents who were informed about the study and asked to give consent, 160 parents returned the letters of statement signed. From those 160 children there were 6 who either did not want to participate to the interviews or missed too many days during the interventions.

\subsection{Data Collection}

The children's achievement was measured through individual structured interviews. Three different interview protocols were designed by the authors, one for each intervention. The interview protocols were employed twice for each child, as pre- and post-tests were necessary to evaluate the progress of the child's ideas about the related concepts of the interventions. In particular, the three interview protocols were: "Protection of wild animals", "Healthy lifestyle" and "Books".

Each protocol was designed according to the learning goals of the corresponding intervention and followed the principles of the developmentally appropriate approach on data collection methods (Einarsdóttir, 2007; Christian, Pearce, Roberson, \& Rothwell, 2010; Mauthner, 1997; Punch, 2002), in order to adjust them to kindergarten children's features and, ensure the credibility of the data collection procedure (Irwin \& Johnson, 2005; Mahon, Gleddinning, Clarke, \& Craig, 1996).

The interview protocols included a variety of close-ended and open-ended questions, combined with a range from structured activities, such as problem-solving situations (Christian et al., 2010), classification/categorization of pictures (Punch, 2002), role play (Irwin \& Johnson, 2005) etc. Therefore, the interview procedure was an authentic playful activity, where children presented high levels of engagement (Einarsdóttir, 2007).

Specifically, the "Protection of wild animals" protocol included 13 items (4 close-ended questions, 4 open-ended questions and 5 structured activities with pictures and toys) and lasted 12 minutes approximately. Moreover, it was divided into three dimensions, in alignment to the related intervention's learning goals, which were "Endangered species" (8 items), "Animals in captivation" (2 items) and "Animal rights" (3 items).

The "Healthy lifestyle" protocol included 7 items ( 2 open-ended questions and 5 structured activities, such as puzzles, categorization and selection of pictures) and lasted 15 minutes approximately. The interview was also divided into three dimensions, like the previous protocol, which were "My body and how to be healthy" ( 2 items), "Healthy diet" (3 items) and "Physical activity" ( 2 items).

Similarly, the "Books" protocol included in total 7 items (3 close-ended questions, 2 open-ended questions and 2 structured activities, namely role play and sequencing cards). The average duration of the "Book" interviews was $10 \mathrm{mi}$ nutes and it was composed by the dimensions: "Types of books" ( 2 items), "Jobs related to books" ( 2 items) and "Joy of reading" (3 items).

\subsection{Data Analysis}

The collected answers of each child at each interview were graded depending on 
how close they were to the learning goals of the corresponding intervention. In other words, the more the answer was aligned with the learning goals, the higher it was graded in a 4 -graded scale ( 3 = very close and close, $2=$ quite close, $1=$ quite away or not so close, 0 = away or no answer at all) (for example, see Table 1). The close-ended questions, as well as the structured activities were directly graded, but the procedure for the open-ended questions was slightly different, as the qualitative Content Analysis preceded the grading. Particularly, the open-ended questions were analyzed in NVivo 10 program and the categories and codes that emerged were then evaluated and graded accordingly. This procedure was followed for both pre- and post-tests at each protocol, in order to acquire quantitative data that could easily be compared through appropriate statistical tests. As a result, the compared means was the analyzing method at the SPSS program.

\subsection{Procedure}

The procedure for both the experimental and the control group was the same: pretests, intervention and posttests. The only difference between the two groups was the type of teaching approach, since children from the experimental group participated in differentiated interventions, while the control group participated in interventions developed on the "teaching to the middle" approach.

Regarding the interview procedure, each child was alone with the interviewer ( $1^{\text {st }}$ author) at a quiet place into the school setting and during the school hours. After "breaking the ice" with a short conversation the interview protocol was employed. Although, the protocols were structured, clarifying questions were asked when needed. The interviews were audiotaped and, then transcribed.

Since the interventions were three and there were pre- and post-tests for each protocol, every child participated in total in 6 interviews. Indeed, the data collection procedure lasted 7 months (December 2016-June 2017) and followed the sequence that Figure 1 presents. More specifically, each intervention was implemented 1 - 4 weeks after the pre-tests, while the post-tests took place 2 - 6 weeks after the end of the intervention. The "Protection of wild animals" intervention lasted 4 weeks and was applied between the middle of January to the middle of February 2017, the "Healthy lifestyle" intervention lasted 5 weeks and was applied during March 2017 and the last intervention "Books" lasted 3 weeks

Table 1. Examples of grading the children's answers from different types of questions.

\begin{tabular}{ccccc}
\hline Type of question & $\mathbf{3}$ & $\mathbf{2}$ & 1 & $\mathbf{0}$ \\
\hline Close-ended & Yes & Maybe & No & $\begin{array}{c}\text { No answer/ } \\
\text { Don't know }\end{array}$ \\
Open-ended & $\begin{array}{c}\text { Explained } \\
\text { sufficiently }\end{array}$ & $\begin{array}{c}\text { Explained } \\
\text { partly } \\
\text { Activity }\end{array}$ & $\begin{array}{c}\text { Explained } \\
\text { insufficiently } \\
\text { all the times or } \\
\text { most of the times }\end{array}$ & $\begin{array}{c}\text { No answer/ } \\
\text { Don't know }\end{array}$ \\
\hline
\end{tabular}




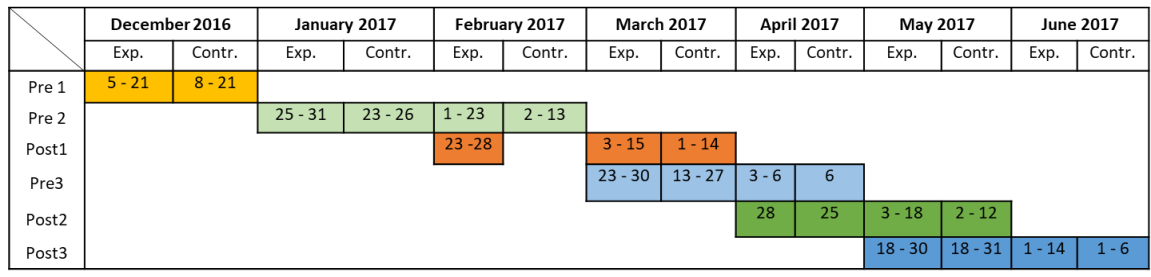

Figure 1. Pre- and post-tests sequences at both groups.

and was implemented from the end of March to the middle of May 2017, due to Easter vacations that intervened.

The groups of teachers selected the themes that were developed in instructional activities after separate group meetings. The selection was a combination of researchers' proposals, children's interests and teacher's decisions to participate in several projects (e.g. environmental projects were aligned with the "Protection of wild animals" theme) during that school year. After defining the themes, the two groups of teachers had 2 meetings, initially to set the learning goals, and subsequently to modify a series of activities that the researchers designed. As the meetings were separate for the two groups, the teachers of the experimental group discussed and co-designed the interventions according to DI, while teachers of the control group worked with interventions designed for the middle level of the class. Nonetheless, the two types of interventions did not differ in other aspects, but only in the existence or not of the DI approach. To achieve this, the interventions were initially designed according to the traditional teaching approach and were subsequently differentiated according to children's existing ideas, readiness levels in literacy and mathematical skills, interests and learning styles. The children's characteristics were assessed by systematic observation by the participating teachers, while pre-tests had revealed the existing ideas of kindergarteners on the specific themes. As a result, all the teachers from each group applied the same activities aiming at the same fundamental learning goals, merely differing in the teaching approach.

\subsection{Reliability and Validity Issues}

The equation of the two groups is always an issue in the quasi-experimental designs. However, in the present study the children had similar characteristics regarding the sex, age and location of schools, along with their teachers who also had similar years of experience and education levels. Moreover, the pre-tests would highlight any previous differences between the two groups, which should be considered in the analysis.

To secure the consistency of the interventions inside the two groups, the researchers: 1) provided the teachers with pre-designed activities, 2) had meetings prior to the intervention with teachers of both groups separately, so as they would agree in the exact modifications they were going to make, 3) were constantly present at the schools to conduct the interviews with the children, thus having the chance to observe the exact application of the interventions, and 4) 
had several personal and group meetings with the teachers from both groups to discuss the applications and support them to deal with any emerging constraints. Based on the meetings, the observations and children's documentation, no major variations inside each type of intervention occurred.

Another major threat that researchers attempted to prevent was the repetition of the same interview, as pre- and post-tests were conducted. To reassure that children would not give different answers just because they were more familiar with the interview protocol, long time gaps mediated between pre- and post-test of the same protocol, namely at least 7 weeks. On top of that each protocol included a combination of questions that measured the same concept in order to detect any contradictions.

\section{Curriculum Adjustments on Thematic Integrated Interventions According to Differentiated Instruction}

The procedure for each intervention was to initially design the activities according to the New Curriculum for Kindergarten (Institute of Educational Policy, 2014), following the "teaching to the middle" approach, as usually teachers do. Afterwards, the interventions were adjusted following the DI approach of teaching to address the readiness levels, the interests and the learning types of the participant kindergarteners.

As the DI approach proposes different types of curriculum, adjustments were applied. Firstly, the content of instruction was tailored to children's readiness levels and learning styles, while no differentiation based on interests occurred (Figure 2). In this case, the readiness levels referred to the different reading skills, as well as the existing ideas of children about the specific concepts of the intervention. The reading skills were systematically evaluated by the teachers, while the existing ideas were collected through the pre-tests by the interviewer. Consequently, when the learning goals required children to use reading materials, the teachers organized the materials by their level of difficulty.

As a result, different readiness groups were provided with the appropriate reading materials, thus facilitating their investigations. For example, under the "Protection of the wild animals" theme, there was an activity that aimed to the investigation of protection practices from different organizations, where children were encouraged to find and report those practices. According to their reading skills the less advanced readers watched a video and painted the practices

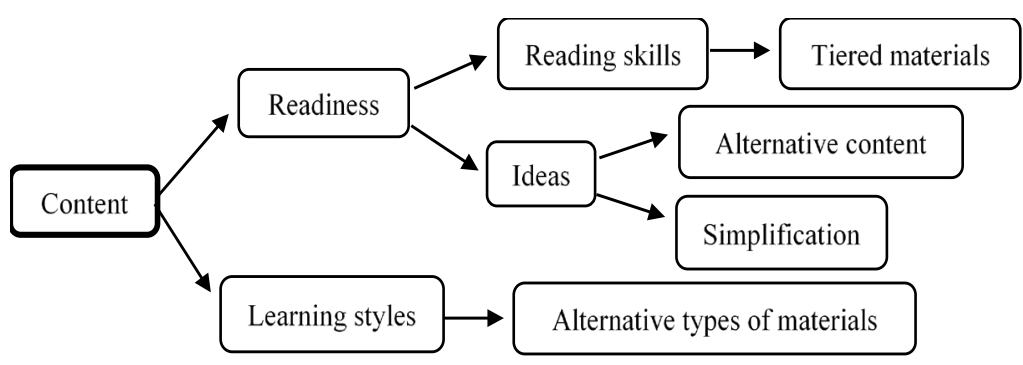

Figure 2. Differentiations of content. 
they remembered, the medium readers used a book with small texts and some cards with titles from inside the book and the more advanced readers worked with more complicated texts from an organization's informational leaflet (Figure 3 ). In any group, the teacher provided additional help and sometimes red parts of the materials.

Additionally, when the existing ideas varied significantly, teachers tailored the content of their instruction by providing alternative content or by varying the difficulty level of the activity. A characteristic example of how alternation of the content was applied was when, under the "Healthy lifestyle" theme, the children who believed that people catch flus and viruses just because they eat a lot of candies, played a kinetic game that entered them to the concept of contagion of germs by using glitter as supposed germs. Another group, who believed that cold weather is the mere reason why people get sick, watched a video breaking this myth. Finally, the last group who recognized that there is something contagious but couldn't describe the germs, read a book with their teacher about the way germs become contagious.

The content was also adjusted to match the different learning styles. Although, learning styles are not yet established in early years, teachers observed a tendency to a specific learning style at each kindergartener. The differentiation based on learning styles was accomplished with different types of materials, namely visual, audio and kinesthetic activities and materials. Indeed, the use of different types of materials were apparent every time that teachers selected to respond to learning styles, regardless if they modified the content, the process or the product of instruction.

Another aspect of the applied curriculum that was usually adjusted to meet the needs of all learners was the procedure. The adjustments followed the same patterns that were revealed from the differentiation of the content (Figure 4).
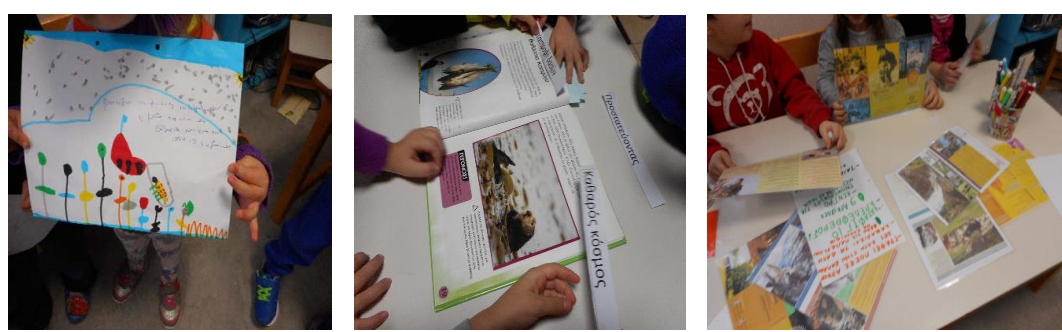

Figure 3. Example of differentiation of content by providing tiered materials.

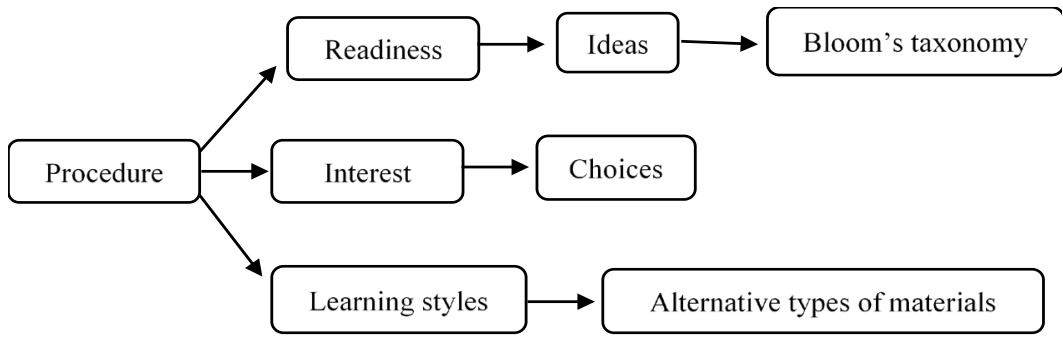

Figure 4. Differentiations of teaching procedure. 
Additionally, at the differentiation by readiness the design of the tiered activities followed either an alternative design for each group of children or the tiering of learning activities by Bloom's taxonomy. During the theme "Books", the activity was designed to provide more support. The materials aimed at the "knowledge" level for those who couldn't recognize any category of books (e.g. fairy tale, comic etc.). The children who categorized appropriately some books took less support and the activity aimed at the "comprehension" level, as they had to compose a page from each category by using a prototype. At the same time, the more advanced group synthesized and applied their comprehension of the different characteristics of the books, as they worked on the "application" level of Bloom's taxonomy. Moreover, to address the children's different interests, teachers provided a range of different activities to select the activity they were more interested to engage in. Similar to the differentiation based on the learning styles, the response to interests followed the same pattern regardless of the phase of the instruction, which is the strategy of choices.

Last but not least, the product of instruction was adjusted either by readiness or by interest or by addressing readiness and interests simultaneously (Figure 5). As differentiation by readiness or by interests was previously analyzed, the combination of differentiating according to readiness and interests was an innovation for teachers and thus emerged by the end of the third intervention, when teachers and children were quite familiar with DI. Therefore, the jigsaw strategy was implemented as a more advanced way to flexible grouping and completed in two steps: initially, children selected a job they were interested from the "Books" theme and, subsequently they formed readiness groups (according to writing skills) in order to deploy their "expertise" (e.g. as writers, illustrators or typographers) to compose their own books.

\section{Results}

The impact of curriculum adjustments according to the DI approach on children's achievement were investigated through the Mann-Whitney $\mathrm{U}$ and Wilcoxon statistical tests, since the data did not satisfy the regularity condition.

\subsection{Differences between and Inside the Groups}

Firstly, to study the differences between the two groups of children, MannWhitney $U$ test for independent groups was employed for each intervention. Specifically, at the $1^{\text {st }}$ intervention "Protection of the wild animals", the experimental

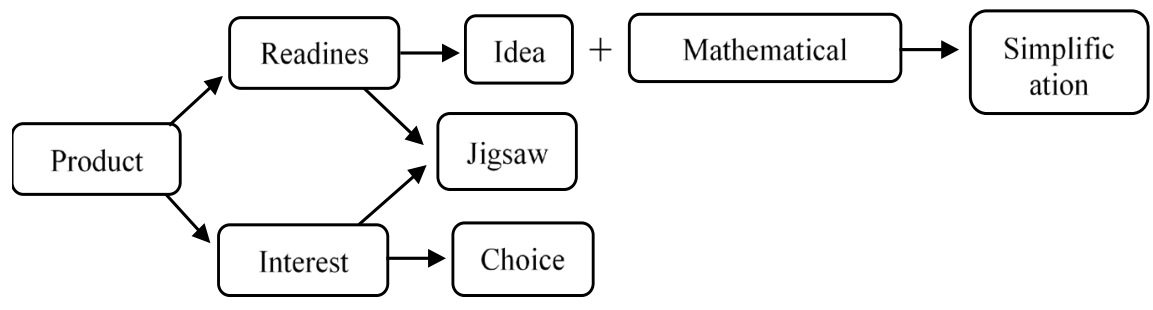

Figure 5. Differentiations of product. 
group $(M d n=19)$ did not differ from the control group $(M d n=19)$ in pre-tests, $U=2811, p=.29$, but after the intervention there were significant differences on favor of the DI approach $(M d n=35)$ than "teaching to the middle" approach $(M d n=27), U=1103.5, p<.001$. Similarly, at the $2^{\text {nd }}$ intervention "Healthy lifestyle" there were initially no differences between experimental $(M d n=12)$ and control group $(M d n=12.5), U=2899, p=.41$, but the post-tests revealed that children who participated in DI achieved significantly higher the learning goals $(M d n=18.5)$ than their peers from the other group $(M d n=14), U=1058, p$ $<.001$. In addition, at the $3^{\text {rd }}$ intervention "Books", the two groups presented a difference between them, with the experimental group scoring a little higher $(M d n=12)$ than the control group $(M d n=11), U=2181.5, p=.04$. This achievement gap occurred after the intervention and increased, too. Therefore, the post-test showed that experimental group gathered significantly higher scores $(M d n=18)$ comparing to the kindergarteners from the control group $(M d n=14), U=668, p<.001$.

Secondly, to investigate the effectiveness of each intervention inside each group Wilcoxon tests for dependent groups were applied. Statistical differences occurred in every intervention at the control group $(N=74)$. Indeed, the $1^{\text {st }}$ intervention "Protection of wild animals" changed their initial ideas, as post-tests scores were higher $(M d n=27)$ than pre-tests $(M d n=19), Z=6.62, p<.001$. The same results occurred for the $2^{\text {nd }}$ intervention "Healthy lifestyle" $\left(M d n_{p r e}=\right.$ $\left.12.5, M d n_{\text {post }}=14, Z=3.38, p<.001\right)$, and the $3^{\text {rd }}$ intervention "Books" $\left(M d n_{\text {pre }}\right.$ $=11, M d n_{\text {post }}=14, Z=3.49, p<.001$ ), hence approving the effectiveness of the interventions in achieving the learning goals. In addition, Table 2 describes that the majority of children from the control group achieved higher after the interventions, specifically at the $1^{\text {st }}$ intervention.

Table 2. Descriptive statistics of control's group ranks at pre- and post-tests of interventions.

\begin{tabular}{|c|c|c|c|c|}
\hline \multicolumn{5}{|c|}{ Ranks $^{\mathrm{a}}$} \\
\hline & & $\mathbf{N}$ & Mean rank & Sum of ranks \\
\hline \multirow{4}{*}{ Post-test 1 - Pre-test 1} & Negative ranks & $8^{\mathrm{b}}$ & 18.50 & 148.00 \\
\hline & Positive ranks & $65^{c}$ & 39.28 & 2553.00 \\
\hline & Ties & $1^{\mathrm{d}}$ & & \\
\hline & Total & 74 & & \\
\hline \multirow{4}{*}{ Post-test 2 - Pre-test 2} & Negative ranks & $21^{\mathrm{e}}$ & 30.71 & 645.00 \\
\hline & Positive ranks & $48^{\mathrm{f}}$ & 36.88 & 1770.00 \\
\hline & Ties & $5^{g}$ & & \\
\hline & Total & 74 & & \\
\hline \multirow{4}{*}{ Post-test 3 - Pre-test 3} & Negative ranks & $18^{\mathrm{h}}$ & 28.83 & 519.00 \\
\hline & Positive ranks & $46^{\mathrm{i}}$ & 33.93 & 1561.00 \\
\hline & Ties & $10^{j}$ & & \\
\hline & Total & 74 & & \\
\hline
\end{tabular}

a. Group = control; b. Post-test $1<$ Pre-test 1 ; c. Post-test $1>$ Pre-test 1 ; d. Post-test $1=$ Pre-test 1 ; e. Post-test $2<$ Pre-test 2; f. Post-test $2>$ Pre-test 2; g. Post-test 2 = Pre-test 2; h. Post-test $3<$ Pre-test 3; i. Post-test $3>$ Pre-test 3; j. Post-test $3=$ Pre-test 3 . 
Moreover, the Wilcoxon test for the experimental group $(N=80)$ also revealed that every intervention changed significantly their initial ideas. In particular, the "Protection of wild animals" intervention was effective in achieving the learning goals, as post-test scores were significantly higher $(M d n=35)$ than the pre-test scores $(M d n=19), Z=7.76, p<.001$. Accordingly, the same results were repeated in the $2^{\text {nd }}$ intervention $\left(M d n_{p r e}=12, M d n_{p o s t}=18.5, Z=7.59, p\right.$ $<.001)$ and the $3^{\text {rd }}$ intervention $\left(M d n_{p r e}=12, M d n_{p o s t}=18, Z=7.73, p<.001\right)$, thus highlighting that all of them were effective interventions (Table 3 ). Comparing Table 2 and Table 3 is obvious that almost every child from the experimental group approached the learning goals rather than those from the control group.

\subsection{Differences among Curriculum Adjustments}

In order to detect any possible differences on children's achievement depending on the applied types of differentiation, Wilcoxon test for dependent samples was employed only for both groups. However, the rationale we followed was:

- If the scores of two concepts inside an intervention differed significantly in both groups of children, then the concept with the higher score was considered as easier than the other one to be comprehended by kindergarteners;

- If the scores of two concepts inside an intervention did not differ in both groups, then those concepts were considered as equally easy or difficult to be comprehended;

- If the score of one concept differed significantly from another concept inside an intervention, but only at the experimental group and not at the control group, then we assumed that the teaching approach was the factor that contributed to the better comprehension. Note that, the opposite, i.e. differences between two concepts existing only at the control and not the experimental group, did not occur at this study.

Table 3. Descriptive statistics of experimental's group ranks at pre- and post-tests of interventions.

\begin{tabular}{|c|c|c|c|c|}
\hline \multicolumn{5}{|c|}{ Ranks $^{\mathrm{a}}$} \\
\hline & & $\mathbf{N}$ & Mean rank & Sum of ranks \\
\hline \multirow{4}{*}{ Post-test 1 - Pre-test 1} & Negative ranks & $1^{\mathrm{b}}$ & 2.50 & 2.50 \\
\hline & Positive ranks & $79^{c}$ & 40.98 & 3237.50 \\
\hline & Ties & $0^{\mathrm{d}}$ & & \\
\hline & Total & 80 & & \\
\hline \multirow{4}{*}{ Post-test 2 - Pre-test 2} & Negative ranks & $2^{\mathrm{e}}$ & 14.75 & 29.50 \\
\hline & Positive ranks & $77^{\mathrm{f}}$ & 40.66 & 3130.50 \\
\hline & Ties & $1^{\mathrm{g}}$ & & \\
\hline & Total & 80 & & \\
\hline \multirow{4}{*}{ Post-test 3 - Pre-test 3} & Negative ranks & $0^{\mathrm{h}}$ & .00 & .00 \\
\hline & Positive ranks & $79^{\mathrm{i}}$ & 40.00 & 3160.00 \\
\hline & Ties & $1^{j}$ & & \\
\hline & Total & 80 & & \\
\hline
\end{tabular}

a. Group $=$ experimental; b. Post-test $1<$ Pre-test 1 ; c. Post-test $1>$ Pre-test 1 ; d. Post-test $1=$ Pre-test 1 ; e. Post-test $2<$ Pre-test 2; f. Post-test $2>$ Pre-test 2; g. Post-test $2=$ Pre-test 2 ; h. Post-test $3<$ Pre-test 3; i. Post-test $3>$ Pre-test 3; j. Post-test $3=$ Pre-test 3 . 
As a result, when the third hypothesis occurred the specific concepts were matched to the types of differentiation that instruction included, namely response to readiness, interest and learning styles, in order to identify which type seems to have the most positive impact on achievement. Thus, no type of differentiation was found to be more effective at the $1^{\text {st }}$ intervention "Protection of wild animals", while at the $2^{\text {nd }}$ intervention "Healthy lifestyle" specific types of differentiation seemed to be more effective. Particularly, when teachers responded to interests, then children achieved higher $(M d n=3)$ than differentiation by readiness $(M d n=3)(Z=2.072, p=.022)$. At the same time there were two different instances which validated that addressing the readiness levels was a more effective way of teaching than differentiation by learning styles: a) in the first instance the scores after differentiation by readiness $(M d n=3)$ were significantly higher than the scores after differentiation by learning styles $(M d n=2) Z$ $=1.814, p=.038$, and $\mathrm{b})$ in the second instance the scores after differentiation by readiness $(M d n=3)$ were once again higher than those after differentiation by learning styles $(M d n=2), Z_{2}=3.605, p<.001$. Moving on to the $3^{\text {rd }}$ intervention "Books", like the $1^{\text {st }}$ intervention, no type of differentiation seemed to have greater effect on achievement.

\section{Discussion}

This study attempted to respond to the need for definition of specific aspects and types of differentiation adjustments in the everyday applied curriculum (Subban, 2006; Tomlinson et al., 2003), as well as to examine the effectiveness of DI in the kindergarten settings. The results revealed that DI was completely compatible with kindergarten education, along with the Integrated Curriculum and was proved to be an effective teaching approach. These results are aligned with the previous research that revealed the positive impact of DI on students from elementary to college levels of education (e.g. Martin \& Pickett, 2013; Konstantinou-Katzi, et al., 2013; Little, McCoach, \& Reis, 2014), and also indicated the applicability and the positive impact of DI in kindergarten (Wu \& Chang, 2015).

Consequently, kindergarten is a fertile ground for the DI approach and more research could shed light onto the strategies and the techniques of DI that are more suitable for this age of children. The differentiation strategies implemented in this study (e.g. choices, flexible grouping, tiered activities and materials) were successful in advancing children's achievement (Baumgartner, Lipowski, \& Rush, 2003; Koeze, 2007; Tieso, 2005). Indeed, the differentiation by interests, which incorporated the choice strategy, was found more effective than responding to readiness and learning styles. A possible reason for this result may be that choice providing freedom to children and a way to express their own voices in the classroom, which was referred by Tomlinson (2005) as important and influential in learning. However, the provision of choices was not always a quality strategy, as teachers observed that children sometimes selected an activity with friendship or convenience criteria. Indeed, Danzi, Reul, \& Smith (2008) indicated that child- 
ren chose the same type of activity, because it seemed a safer option, thus undermining the challenging level of instruction. Therefore, several concerns emerge regarding whether the teacher should intervene on children's free will and how this strategy could be better organized and applied. Obviously, it is necessary to define and optimize the existing strategies, though such insights can only occur after constant application of DI in real classrooms.

On the other hand, differentiation by learning styles was proved to be less effective than the other two types of differentiation (i.e. interests and readiness). It is possible that learning styles are neither quite established nor distinctive, due to children's young age (Middendorf, 2008). Teachers frequently observed that some children covered the requirements of two different learning styles, for example being kinesthetic and oral type. In addition, they sometimes realized that over the time some kindergarteners moved to another type than they had previously presented. Therefore, addressing the learning styles might become a confusing procedure for teachers and not quite successful, too.

When comparing the DI approach with the traditional model of instruction, the results indicated that one-size-fits-all teaching could lead to learning achievement, but not for all learners. In particular, the traditional approach did not facilitate the maximum performance for all the children, while DI took their ideas further, as they achieved significantly higher scores. In other words, traditional teaching was able to contribute in merely achieving the learning goals, but DI extended children's initial ideas beyond the medium level of the class, allowing every learner to succeed. A follow-up research would reveal whether these ideas transformed into attitudes and long-term learning occurred.

Furthermore, the results demonstrated that DI was compatible with the Integrated Curriculum, an issue that had not been studied before. Indeed, DI proved to have positive impact not only on achievement of fragmented subject areas, but also on the framework of integrated themes when basic ideas constitute the learning goals of instruction.

\section{Limitations and Further Research}

The present study did not investigate whether different groups of kindergarten children would benefit greater than their peers from DI, as previous research indicated. Thus, the gathered demographic data did not include any information related to the socio-economic status of participants and/or their ethnicity. Future research should gather more demographic data, allowing further intercorrelations.

The specific types of differentiating the instruction that were presented here do not imply that other combinations and adjustments are not applicable for kindergarten. The discussion about the specific adjustments is concentrated on the fact that these combinations have been found applicable and their effectiveness is still under further research. Consequently, a limitation was that the results indicated a possible tendency and not a proof that there were types of dif- 
ferentiation that may have a more positive impact than others, as a larger number of activities under each type of differentiation could verify whether this tendency was accurate. Moreover, further research is necessary to shed light onto the different aspects of DI and their effectiveness.

\section{Acknowledgements}

The research work was supported by the Hellenic Foundation for Research and Innovation (HFRI) and the General Secretariat for Research and Technology (GSRT), under the HFRI PhD Fellowship grant (GA. No. 2424).

\section{Conflicts of Interest}

The authors declare no conflicts of interest regarding the publication of this paper.

\section{References}

Bantis, A. M. (2008). Using Task-Based Writing Instruction to Provide Differentiated Instruction for English Language Learners. Master's Dissertation, Los Angeles, CA: University of Southern California.

Baumgartner, T., Lipowski, M. B., \& Rush, C. (2003). Increasing Reading Achievement of Primary and Middle School Students through Differentiate Instruction. Master's Dissertation. Chicago, IL: Saint Xavier University.

Beane, J. (1991). The Middle School: The Natural Home of Integrated Curriculum. Educational Leadership, 49, 9-13. https://eric.ed.gov/?id=EJ432772

Brennan, S. A. (2008). Differentiated Instruction and Literacy Skill Development in the Preschool Classroom. Ph.D. Dissertation, Ames, IA: Iowa State University.

Cassidy, S. (2004). Learning Styles: An Overview of Theories, Models, and Measures. Educational Psychology, 24, 419-444. https://doi.org/10.1080/0144341042000228834

Christensen, L. B. (2004). Experimental Methodology (9th ed.). Boston, NY: Pearson Education.

Christian, B. J., Pearce, P. F., Roberson, A. J., \& Rothwell, E. (2010). It's a Small, Small World: Data Collection Strategies for Research with Children and Adolescents. Journal of Pediatric Nursing, 25, 202-214. https://doi.org/10.1016/j.pedn.2009.01.003

Coubergs, C., Struyven, K., Vanthournout, G., \& Engels, N. (2017). Measuring Teachers' Perceptions about Differentiated Instruction: The DI-Quest and Model. Studies in Educational Evaluation, 53, 41-54. https://doi.org/10.1016/j.stueduc.2017.02.004

Danzi, J., Reul, K., \& Smith, R. (2008). Improving Student Motivation in Mixed Ability Classrooms Using Differentiated Instruction. Master's Dissertation, Chicago, IL: Saint Xavier University \& Pearson Achievement Solutions, Inc.

DeBaryshe, B. D., Gorecki, D. M., \& Mishima-Young, L. N. (2009). Differentiated Instruction to Support High-Risk Preschool Learners. NHSA Dialog, 12, 227-244. https://doi.org/10.1080/15240750903075305

Dimitropoulou, P. (2013). Classroom and Differentiated Instruction: Presuppositions to Create an Effective Learning Environment. In S. Panteliadou, \& D. Filipatou (Eds.), Differentiated Instruction: Theoretical Approaches and Educational Practices (pp. 121-148). Athens: Pedio. (In Greek)

Einarsdóttir, J. (2007). Research with Children: Methodological and Ethical Challenges. 
European Early Childhood Education Research Journal, 15, 197-211. https://doi.org/10.1080/13502930701321477

Elliott, S. N., Kratochwill, T. R., Cook, J. L., \& Travers, J. F. (2008). Educational Psychology. Translated \& Edited by M. Solman, F. Kalyva, A. Leontari, \& E. Syggolitou. Athens: Gutenberg. (In Greek)

Ernest, J. M., Heckaman, K., Thompson, S., Hull, K. M., \& Carter, S. W. (2011). Increasing the Teaching Efficacy of a Beginning Special Education Teacher Using Differentiated Instruction: A Case Study. International Journal of Special Education, 26, 191-201. https://eric.ed.gov/?id=EJ921209

Faber, J. M., Glas, C. A. W., \& Visscher, A. J. (2018). Differentiated Instruction in a Data-Based Decision-Making Context. School Effectiveness and School Improvement, 29, 46-63. https://doi.org/10.1080/09243453.2017.1366342

Ford, N. (1995). Levels and Types of Mediation in Instructional Systems: An Individual Differences Approach. International Journal of Human-Computer Sciences, 43, 241-259. https://doi.org/10.1006/ijhc.1995.1043

Ford, N., \& Chen, S. Y. (2001). Matching/Mismatching Revisited: An Empirical Study of Learning and Teaching Styles. British Journal of Educational Technology, 32, 5-22. https://doi.org/10.1111/1467-8535.00173

George, P. S. (2005). A Rationale for Differentiating Instruction in the Regular Classroom. Theory into Practice, 44, 185-193. https://doi.org/10.1207/s15430421tip4403_2

Gregory, G. H., \& Chapman, C. (2007). Differentiated Instructional Strategies. Newbury Park, CA: Corwin Press.

Hall, T. (2002). Differentiated Instruction. Effective Classroom Practices Report, National Center on Accessing the General Curriculum, Office of Special Education Programs, U.S. Department of Education.

Heacox, D. (2002). Differentiating Instruction in the Regular Classroom. Minneapolis, MN: Free Spirit Publishing.

Institute of Educational Policy (2014). New Curriculum for Kindergarten. Athens: Ministry of Education, Research and Religious Affairs. (In Greek)

https://repository.edulll.gr/edulll/retrieve/7058/1947_1\%CE\%BF\%20\%CE\%BC\%CE\%A D\%CF\%81\%CE\%BF\%CF\%82\%20\%CE\%A0\%CE\%A0\%CE\%A3\%20\%CE\%BD\%CE\%B7 \%CF\%80\%CE\%B9\%CE\%B1\%CE\%B3\%CF\%89\%CE\%B3\%CE\%B5\%CE\%AF\%CE\%BF \%CF\%85.pdf

Irwin, L. G., \& Johnson, J. (2005). Interviewing Young Children: Explicating Our Practices and Dilemmas. Qualitative Health Research, 15, 821-831. https://doi.org/10.1177/1049732304273862

Kakana, D., \& Mavidou, A. (2015). Myth and Antinomy in Early Childhood Education: Formal vs. Applied Curricula and Professional Development. US-China Education Review $B, 5,780-793$.

Koeze, P. A. (2007). Differentiated Instruction: The Effect on Student Achievement in an Elementary School. PhD Thesis, Ypsilanti, MI: Eastern Michigan University.

Konstantinou-Kantzi, P., Tsolaki, E., Meletiou-Mavrotheris, M., \& Koutselini, M. (2013). Differentiation of Teaching and Learning Mathematics: An Action Research Study in Tertiary Education. International Journal of Mathematical Education in Science and Technology, 44, 332-349. https://doi.org/10.1080/0020739X.2012.714491

Landrum, T. J., \& McDuffie, K. A. (2010). Learning Styles in the Age of Differentiated Instruction. Exceptionality: A Special Education Journal, 18, 6-17.

https://doi.org/10.1080/09362830903462441 
Levine, M. (2003). Celebrating Diverse Minds. Educational Leadership, 61, 12-18. http://www.ascd.org/publications/educational-leadership/oct03/vol61/num02/Celebrati $\underline{\text { ng-Diverse-Minds.aspx }}$

Lewis, S. G., \& Batts, K. (2005). How to Implement Differentiated Instruction? Adjust, Adjust, Adjust. Journal of Staff Development, 26, 26-31. https://eric.ed.gov/?id=EJ752247

Little, C. A., McCoach, D. B., \& Reis, S. M. (2014). Effects of Differentiated Reading Instruction on Student Achievement in Middle School. Journal of Advanced Academics, 25, 384-402. https://doi.org/10.1177/1932202X14549250

Mahon, A., Glendinning, C., Clarke, K., \& Craig, G. (1996). Researching Children: Methods and Ethics. Children and Society, 10, 145-154. https://doi.org/10.1111/j.1099-0860.1996.tb00464.x

Martin, M. R., \& Pickett, M. T. (2013). The Effects of Differentiated Instruction on Motivation and Engagement in Fifth-Grade Gifted Math and Music Students. Master Thesis, Chicago, IL: Saint Xavier University.

Mauthner, M. (1997). Methodological Aspects of Collecting Data from Children: Lessons from Three Research Projects. Children and Society, 11, 16-28.

https://doi.org/10.1111/j.1099-0860.1997.tb00003.x

Middendorf, C. (2008). Differentiating Instruction in Kindergarten. Scholastic Inc.

Morgan, H. (2014). Maximizing Student Success with Differentiated Learning. The Clearing House, 87, 34-38. https://doi.org/10.1080/00098655.2013.832130

Pask, G. (1976). Styles and Strategies of Learning. British Journal of Educational Psychology, 46, 128-148. https://doi.org/10.1111/j.2044-8279.1976.tb02305.x

Punch, S. (2002). Research with Children: The Same or Different from Research with Adults? Childhood, 9, 321-341. https://doi.org/10.1177/0907568202009003005

Reis, S. M., McCoach, D. B., Little, C. A., Muller, L. M., \& Kaniskan, R. B. (2011). The Effects of Differentiated Instruction and Enrichment Pedagogy on Reading Achievement in Five Elementary Schools. American Educational Research Journal, 48, 462-501. https://doi.org/10.3102/0002831210382891

Rock, M., Gregg, M., Ellis, E., \& Gable, R. A. (2008). REACH: A Framework for Differentiating Classroom Instruction. Preventing School Failure, 52, 31-47. https://doi.org/10.3200/PSFL.52.2.31-47

Roy, A., Guay, F., \& Valois, P. (2013). Teaching to Address Diverse Learning Needs: Development and Validation if a Differentiated Instruction Scale. International Journal of Inclusive Education, 17, 1186-1204. https://doi.org/10.1080/13603116.2012.743604

Santamaria, L. (2009). Culturally Responsive Differentiated Instruction: Narrowing Gaps between Best Pedagogical Practices Benefiting All Learners. Teachers College Record, 111, 214-247. https://eric.ed.gov/?id=EJ826003

Scott, B. (2012). The Effectiveness of Differentiated Instruction in the Elementary Mathematics Classroom. PhD Thesis, Indiana: Ball State University.

Scott, B. J., Vitale, M. R., \& Masten, W. G. (1998). Implementing Instructional Adaptations for Students with Disabilities in Inclusive Classrooms. Remedial and Special Education, 19, 106-119. https://doi.org/10.1177/074193259801900205

Smit, R., \& Humpert, W. (2012). Differentiated Instruction in Small Schools. Teaching and Teacher Education, 28, 1152-1162. https://doi.org/10.1016/j.tate.2012.07.003

Subban, P. (2006). Differentiated Instruction: A Research Basis. International Education Journal, 7, 935-947. https://eric.ed.gov/?id=EJ854351 
Taylor, B. K. (2015). Content, Process, and Product: Modeling Differentiated Instruction. Kappa Delta Pi Record, 51, 13-17. https://doi.org/10.1080/00228958.2015.988559

Tieso, C. (2005) The Effects of Grouping Practices and Curricular Adjustments on Achievement. Journal for the Education of the Gifted, 29, 60-89. https://doi.org/10.1177/016235320502900104

Tobin, R., \& McInnes, A. (2008). Accommodating Differences: Variations in Differentiated Literacy Instruction in Grade 2/3 Classrooms. Literacy, 42, 3-9. https://doi.org/10.1111/j.1467-9345.2008.00470.x

Tobin, R., \& Tippett, C. D. (2014). Possibilities and Potential Barriers: Learning to Plan for Differentiated Instruction in Elementary Science. International Journal of Science and Mathematics Education, 12, 423-443. https://doi.org/10.1007/s10763-013-9414-z

Tomlinson, C. A. (1999). The Differentiated Classroom: Responding to the Needs of All Learners. Alexandria, VA: Association for Supervision and Curriculum Development.

Tomlinson, C. A. (2001). How to Differentiate Instruction in Mixed-Ability Classrooms. Upper Saddle River, NJ: Pearson Education.

Tomlinson, C. A. (2005). Grading and Differentiation: Paradox or Good Practice? Theory into Practice, 44, 262-269. https://doi.org/10.1207/s15430421tip4403_11

Tomlinson, C. A., \& Imbeau, M. B. (2010). Leading and Managing a Differentiated Classroom. Alexandria, VA: ASCD.

Tomlinson, C. A., \& Kalbfleisch, M. L. (1998). Teach Me, Teach My Brain: A Call for Differentiated Classrooms. Educational Leadership, 56, 52-55. https://eric.ed.gov/?id=EJ575232

Tomlinson, C. A., \& McTighe, J. (2004). Integrating Differentiated Instruction and Understanding by Design: Connecting Content and Kids. Alexandria, VA: Association for Supervision and Curriculum Development.

Tomlinson, C. A., Brighton, C., Hertbert, H., Callahan, C. M., Moon, T. R., Brimijoin, K. et al. (2003). Differentiating Instruction in Response to Student Readiness, Interest, and Learning Profile in Academically Diverse Classrooms: A Review of Literature. Journal for the Education of the Gifted, 27, 119-145. https://doi.org/10.1177/016235320302700203

Vygotsky, L. S. (1978). Mind in Society (Translated and Edited by S. Vosniadou, \& A. Bibou). Athens: Gutenberg. (In Greek)

Wu, S.-C., \& Chang, Y.-L. (2015). Advancing Kindergarten Teachers' Knowledge and Capabilities of Differentiated Instruction Associated with Implementation of Thematic Integrated Curriculum. Procedia-Social and Behavioral Sciences, 177, 246-250. 